\title{
Mudança Estrutural, Hiato Tecnológico e Capital Humano em um Modelo Norte-Sul de Crescimento com Restrição de Balanço de Pagamentos
}

\author{
Luciano Ferreira Gabriel ${ }^{1}$ \\ Frederico G. Jayme Jr. ${ }^{2}$ \\ José Luis da Costa Oreiro ${ }^{3}$
}

\section{Resumo}

Este artigo tem como objetivo apresentar um modelo macrodinâmico Kaldoriano em que o processo de convergência ou divergência entre o Norte (desenvolvido) e o Sul (em desenvolvimento) é uma função da mudança estrutural e do hiato tecnológico. A participação da indústria na economia do Sul e o hiato tecnológico se tornaram endógenos para explicar a dinâmica do crescimento compatível com o equilíbrio no Balanço de Pagamentos. Para que ocorra o processo de catching up, há a necessidade do aumento das atividades inovativas do Sul. O modelo desenvolvido exibe equilíbrios múltiplos: um estável e outro instável. No equilíbrio estável, o Sul deve apresentar, conjuntamente, maior desenvolvimento do seu Sistema Nacional de Inovações e elevados efeitos de spillovers industriais em relação ao nível de hiato tecnológico existente.

\section{Palavras-Chave}

Crescimento Econômico. Endogeneidade das Elasticidades. Sistema Nacional de Inovações.

\begin{abstract}
The main objective of this work is to present a macrodynamic Kaldorian model in which the process of convergence or divergence between the North (developed) and the South (developing) is a function of the structural change and technological gap. The manufacturing share in the Southern economy and the technological gap are endogenous and explain the dynamics

- Os autores agradecem os pareceristas anônimos e o Conselho de Desenvolvimento Científico e Tecnológico $(\mathrm{CNPq})$ pelo apoio financeiro.

1 Professor - Universidade Federal de Viçosa - Endereço: Av. Purdue, s/no Campus Universitário Ed. Edson Potsch Magalhães - Viçosa/MG - Brasil - CEP: 36570900 - E-mail: lucianofg@gmail.com ORCiD: https://orcid.org/0000-0002-8321-3022.

2 Professor - Universidade Federal de Minas Gerais - Endereço: Av. Antônio Carlos 6627 Belo Horizonte/MG - Brasil - CEP: 30270-901 - E-mail: gonzaga@cedeplar.ufmg.br.

ORCiD: https://orcid.org/0000-0002-4617-0107.

3 Professor - Universidade de Brasília - Endereço: Campus Universitário Darcy Ribeiro Prédio da FACE - Brasília/DF - Brasil - CEP: 70910-900 - E-mail: jlcoreiro@gmail.com ORCiD: https://orcid.org/0000-0002-4989-2770.

Recebido: 13/01/2017. Aceite: 06/11/2018
\end{abstract}

(c) (i) (\$) Esta obra está licenciada com uma Licença Creative Commons Atribuição-Não Comercial 4.0 Internacional. 
of economic growth compatible with the Balance of Payments equilibrium. In order for the catching up process to take place, there is a need to increase the innovative activities of the South. The developed model exhibits multiples equilibriums: one stable and the other unstable. In the stable equilibrium, the South must present greater development of its National System of Innovations and high effects of industrial spillovers in relation to the existing technological gap.

\section{Keywords}

Economic Growth. Elasticities Endogeneity. National Innovation System.

\section{JEL Classificação}

E12. O11. C22.

\section{Introdução}

O objetivo deste artigo é apresentar um modelo macrodinâmico Kaldoriano do tipo Norte-Sul em que a ocorrência de convergência ou divergência nas taxas de crescimento entre os países é uma função da mudança estrutural (e seus spillovers tecnológicos) e do hiato tecnológico, em um contexto de crescimento impulsionado pela demanda e restrito pelo Balanço de Pagamentos.

A inovação fundamental deste artigo consiste em integrar em um único modelo de crescimento com restrição externa a influência do capital humano, dos esforços em Pesquisa e Desenvolvimento (P\&D), da taxa de câmbio real e da mudança estrutural sobre a dinâmica de uma economia em desenvolvimento, levando-se em conta os efeitos específicos dos spillovers industriais sobre as atividades de inovação.

O conceito de capital humano aqui utilizado é aquele relacionado à perspectiva neoschumpeteriana (ou evolucionária), a qual relaciona a formação educacional dos trabalhadores, bem como o treinamento da mão de obra, como proxies para capacitação tecnológica e potencial de aprendizagem, as quais podem afetar o crescimento por meio do aumento da produtividade e, posteriormente, pelos mecanismos de Kaldor-Verdoorn, o crescimento econômico compatível com a restrição no Balanço de Pagamentos. ${ }^{1}$

1 Essa definição de capital humano utilizada também é bem sintetizada por Lall (1992, 170), em que: "(...) the term human capital is used broadly here to include not just the skills generated by formal education and training, but those created by on-the-job training and experience of technological 
Neste artigo são destacados dois canais não explorados na literatura sobre crescimento econômico com restrição externa em relação aos efeitos da melhoria do capital humano, em termos de sua influência sobre as mudanças na estrutura produtiva e, consequentemente, a razão das elasticidades do comércio internacional. O primeiro canal se dá por meio do chamado "efeito Stiglitz", em que o capital humano, em um modelo orientado pela demanda, pode também afetar a estrutura produtiva a partir de uma maior diversificação dos produtos demandados. O segundo canal é o chamado "efeito Schumpeter-Stiglitz", pelo qual a maior demanda por diversificação de bens de consumo leva ao surgimento de novas inovações de produtos. ${ }^{2}$

Essa perspectiva permite ampliar a capacidade de análise sobre a convergência de renda e catching up tecnológico, enfatizando que o crescimento econômico é um processo de transformação complexo, o qual envolve mudanças estruturais ao longo do tempo, moldadas a partir da interação entre tecnologia, instituições e fatores sociais (Abramovitz 1986). Além disso, o modelo evidencia as principais ideias de Kaldor e Thirlwall sobre o crescimento com restrição externa, em especial a visão path dependence de Kaldor sobre a natureza do processo de crescimento de longo prazo.

Este artigo se insere em uma literatura que tem explorado a questão da chamada endogeneidade das elasticidades e o efeito composição na literatura dos modelos de crescimento com restrição no balanço de pagamentos (doravante modelos BPCG). As elasticidades renda da demanda por importações-exportações serão endógenas porque sua evolução dependente da estrutura produtiva representada pela participação da indústria no PIB do Sul e dos fatores que afetam o hiato tecnológico. ${ }^{3}$ Pode-se observar que a composição setorial da economia importa para o crescimento econômico e que transformações estruturais que impliquem maior participação de setores econômicos com maior elasticidade renda da demanda por exportações afetam positivamente esse crescimento. ${ }^{4}$

activity, and the legacy of inherited skills, attitudes and habilities that aid industrial development." Esse ponto será aprofundado na seção 5. Além disso, a lei de Kaldor-Verdoorn (ou segunda lei de Kaldor) estabelece que há uma relação positiva e forte entre o crescimento da produção manufatureira e o crescimento da produtividade nesse setor, afetando positivamente o crescimento econômico.

2 Nas seções 5 e 6 serão tratados teoricamente e formalmente estes dois efeitos em um contexto de modelos de crescimento com restrição de balanço de pagamentos.

3 Para uma maior discussão em relação à endogeneidade das elasticidades recomendamos Missio, Jayme Jr. e Conceição (2015) e Missio, Araújo e Jayme Jr. (2017).

4 Pode-se definir o chamado efeito composição como aquele que se refere "(...) à mudança das elasticidades provocada pela alteração na pauta de exportações e importações de um determinado país, no que diz respeito tanto à quantidade de bens que compõe a pauta quanto à participação relativa de cada um deles." (Ferrari et al. 2013, 64). 
A participação da indústria na economia, bem como os efeitos da distância tecnológica do Sul em relação ao Norte afetam diretamente a razão das elasticidades, sendo que os efeitos dos spillovers industriais são explicitamente modelados.

Esse processo também depende da dinâmica do hiato tecnológico que no presente artigo é uma função do capital humano, dos investimentos em $\mathrm{P} \& \mathrm{D}$, da capacidade de assimilação de spillovers tecnológicos e do nível do desenvolvimento do Sistema Nacional de Inovações (SI). Conforme poderá ser visto, neste ponto há uma importante conexão com Hausman e Hidalgo et al. (2011), os quais exploram a ideia de que a complexidade econômica reflete o montante de conhecimento embutido na estrutura econômica de um país.

Para cumprir o objetivo proposto o artigo se divide em mais 6 seções, além desta introdução. Na segunda seção é apresentado brevemente o modelo canônico de Thirlwall (1979) e alguns desdobramentos contemporâneos, dentre os quais o presente artigo se insere em termos de tratamento formal. Na terceira seção é apresentado como a mudança estrutural e o hiato tecnológico irão afetar a razão das elasticidades da economia em desenvolvimento (Sul) no modelo. Na quarta seção são apresentados os fundamentos que explicam a relação das capacidades absortiva e sociais, bem como o efeito do Sistema Nacional de Inovações (SI) sobre o hiato tecnológico e a possibilidade de catching up. Na quinta seção é apresentada a interação dinâmica entre capital humano, atividades inovativas e o estoque de conhecimento, afetando o hiato tecnológico. Além disso, são apresentadas as conexões do modelo com o arcabouço teórico da complexidade econômica de Hausman e Hidalgo et. al. (2011). Na sexta seção são realizadas as análises de steady state do modelo e as condições de seu equilíbrio de longo prazo. Além disso, são apresentadas as diferentes condições para ocorrência do catching up tecnológico e crescimento sem restrição externa. Por fim, na última seção são realizadas as considerações finais. 


\section{O modelo BPCG Canônico e a Endogeneidade das Elasticidades do Comércio Internacional}

O ponto inicial do modelo a ser desenvolvido neste artigo segue a abordagem pioneira de Thirlwall (1979 e 1997). Nesse sentido, apresentamos inicialmente esta abordagem e como certos trabalhos desta literatura foram incorporando os efeitos da taxa de câmbio real e da estrutura produtiva sobre o crescimento econômico compatível com equilíbrio no Balanço de Pagamentos. $^{5}$

Partindo-se de Thirlwall (1979 e 1997) e considerando-se que os preços relativos não afetam o equilíbrio do Balanço de Pagamentos no longo prazo, ou seja, que os termos de troca sejam constantes, temos que a taxa de crescimento de equilíbrio com o Balanço de Pagamentos é dada por: ${ }^{6}$

$$
y_{b}=\frac{\varepsilon Z}{\pi}=\frac{x}{\pi}
$$

Ou seja, a taxa de crescimento de equilíbrio com o Balanço de Pagamentos é igual à razão das elasticidades renda das exportações, $\varepsilon$, e importações, $\pi$, multiplicada pela taxa de crescimento da economia mundial, z, ou, em outros termos, é igual à razão entre a taxa de crescimento das exportações $(x=\varepsilon \cdot z)$ e a elasticidade renda da demanda por importações $(\pi)$.

Uma questão importante dentro dessa literatura refere-se ao status das elasticidades-renda, ou seja, se elas podem ser consideradas como variáveis exógenas ao processo de crescimento econômico ou são endógenas a esse mesmo processo. De acordo com Thirlwall (2005), as elasticidades renda dos países são predominantemente determinadas pela dotação de recursos naturais e pelas características dos bens produzidos, os quais são path dependent e independem do crescimento do produto. Nesse sentido, a direção de causalidade vai das elasticidades para o crescimento econômico, ou seja, as elasticidades são exógenas ao processo de crescimento, refletindo a estrutura produtiva.

5 Diferentes modelos são extensões contemporâneas do trabalho canônico à lá Thirlwall, os quais exploram outras possibilidades de convergência e divergência levando-se em conta a competitividade preço e não preço (e.g. Dixon e Thirlwall 1975), a mudança tecnológica e possibilidade de catching up (e.g. Léon-Ledesma 2002), a mudança estrutural (e.g Botta 2009, 2012), efeitos lock in e path dependence (e.g. McCombie e Roberts 2002).

6 Neste caso, assume-se que vale no longo prazo a Paridade do Poder de Compra (PPC), ou seja, os preços relativos não se alteram no longo prazo. 
Um dos primeiros autores a questionar essa relação de causalidade foi Krugman (1989). Sem mencionar claramente o trabalho canônico de Thirlwall, Krugman $(1989,1031)$ afirma que há uma regularidade empírica em que as elasticidades renda das demandas aparentes dos países pelas importações e exportações estejam sistematicamente relacionadas às taxas de crescimento de longo prazo das economias. ${ }^{7}$ Desta forma, países com rápido crescimento apresentam elevadas elasticidades renda da demanda por suas exportações em relação às elasticidades renda das importações, sendo o contrário válido para países de baixo crescimento. Krugman (idem) chama esta regularidade empírica de "regra dos $45^{\circ}$ ".

De acordo com Krugman (1989, 1036-1037) há dois tipos de explicações possíveis para essa regra. A primeira explicação observa que as elasticidades renda poderiam determinar o crescimento, uma vez que países com elasticidade renda das exportações desfavoráveis possam estar incorrendo em problemas no Balanço de Pagamentos. Nesse caso, o resultado poderia ser uma limitação na taxa de crescimento com poucas mudanças na taxa real de câmbio ao longo do tempo. O mesmo resultado ocorreria, segundo o autor, se uma espiral de aumentos dos salários implicasse uma apreciação real do câmbio. A segunda explicação, fundamental para Krugman, é que as diferentes taxas de crescimento dos países afetam o fluxo de comércio de tal forma que criam diferenças nas elasticidades renda, ou seja, a razão das elasticidades de Thirlwall é endógena à taxa de crescimento das economias, as quais são explicadas, principalmente, pela produtividade total dos fatores.

Nesse contexto, Krugman (1989) alega que há elementos do lado da oferta que afetam as diferentes elasticidades renda dos países, de forma que ele inverte a relação de causalidade proposta por Thirlwall (1979). Além disso, sugere que o efeito líquido desta relação nas taxas de câmbio reais é pequeno, de forma que a paridade do poder de compra (PPC) funciona de maneira adequada.

Fica evidente para o autor a primazia do lado da oferta (produtividade total dos fatores) em relação ao lado da demanda no que tange ao crescimento de longo prazo, bem como o fato de que a indústria não possui nenhum papel especial em relação aos retornos crescentes de escala e na

7 As elasticidades aparentes são aquelas em que se consideram como constantes o market share de um determinado país no mercado internacional. 
diferenciação dos produtos exportados, mesmo quando analisa brevemente o processo de catching up do Japão nas décadas de 1950 e $1960 .^{8}$

Mais recentemente a ideia de endogeneidade das elasticidades tem sido desenvolvida em trabalhos nos quais o crescimento de longo-prazo é demand-led. Esses trabalhos podem ser agrupados em duas grandes linhas. A primeira linha enfatiza a relação entre o nível da taxa real de câmbio, a composição da pauta de exportações e a elasticidade renda agregada das exportações. O principal argumento é que o nível da taxa real de câmbio (depreciado) afeta a composição das exportações na direção de bens com maior elasticidade renda, o que termina por aumentar a taxa de crescimento do produto real que é compatível com o equilíbrio do balanço de pagamentos. Nessa linha destacam-se os trabalhos de Araújo (2012), Oreiro et al. (2012), Ferrari, Freitas e Barbosa Filho (2013), Missio (2012), dentre outros. A segunda linha relaciona as elasticidades renda das exportações e das importações com o crescimento passado da economia, como no caso de McCombie e Roberts (2002).

De acordo com McCombie e Roberts (2002), seguindo a visão de Kaldor, o processo de crescimento é histórico dependente, ou seja, é referenciado pela trajetória de crescimento prévio pelo qual uma determinada economia passou (path dependent). Nesse contexto, a razão das elasticidades poderia ser expressa como uma função não-linear: $(\varepsilon / \pi)_{t}=\gamma_{1}+\gamma_{2}\left(\phi-y_{t-1}\right) y_{t-1}$, onde $\gamma_{1}>0$ e $\gamma_{2}>0$.

Nessa formulação $\gamma_{1}, \gamma_{2}$ e $\phi$ são constantes. A razão das elasticidades renda do comércio exterior é uma função do desempenho de crescimento passado da economia $\left(y_{t-1}\right)$. Como pode ser observado, a "Lei de Thirlwall" neste caso é crescente a níveis baixos de $y_{t-1}$ e decrescente em níveis elevados de $y_{t-1}$. Isso reflete a intuição de que baixas taxas de crescimento pregressas podem ensejar pressões por reformas econômicas, enquanto que altas taxas de crescimento podem gerar efeitos lock in.

8 No modelo teórico de Krugman (1989), os ganhos das economias de escala decorrem da vantagem associada à especialização produtiva e nas diferenças na oferta de trabalho para a produção de diferentes bens, em um contexto em que todos os países possuem a possibilidade de produzir qualquer produto. Além disso, o autor concentra muitos dos seus esforços para analisar a produção e o comércio de países já desenvolvidos, ressaltando o papel passivo, ou residual, da taxa de câmbio real. 
Nesse caso, o efeito lock in implica que uma determinada estrutura produtiva pode se tornar pouco competitiva ou ultrapassada reduzindo os valores de $\varepsilon$ e aumentando o valor de $\pi$. Essa estrutura produtiva pode acumular tipos específicos de capital fixo em várias atividades econômicas, gerando dificuldades de mudança ou de incorporação de progresso técnico devido aos custos proibitivos associados às substituições de ativos de produção ou até mesmo com as dificuldades associadas aos processos de tomadas de decisões relacionados, os quais são decentralizadas (Setterfield 2002).

No caso do progresso técnico desse capital fixo, as decisões atuais dependem das passadas devido ao "inter-relacionamento" ou "interconexões" entre os componentes do processo, os quais incluem planta, equipamentos, capital humano e estrutura organizacional (Setterfield 2002).

Outra forma de endogeneizar o processo de crescimento com restrição externa e se adequar dentro dessa categoria de modelos a visão histórica de Kaldor sobre o crescimento econômico é fornecida por Setterfield (1997). Este autor coloca que para economias avançadas o crescimento passado elevado deve ter um efeito negativo sobre as elasticidades da demanda das exportações. Assim, a elasticidade renda das exportações de uma economia é dada por $\varepsilon_{t}=f\left(y_{0}, y_{1}, \ldots, y_{i}, \ldots, y_{t-1}\right)$, onde $d f / d y_{i} \neq 0$. Desta forma, há um efeito feedback no modelo em relação ao desempenho passado da economia sobre a elasticidade renda das exportações, produzindo em contexto de restrição externa, a ideia de path dependence. ${ }^{9}$

Conforme observado nesta seção, a hipótese da endogeneidade das elasticidades apresenta as elasticidades renda do comércio internacional como determinadas por fatores que antes eram considerados exógenos, como a própria mudança da estrutura produtiva, cujo desenvolvimento é path dependent (a exemplo da influência das taxas de crescimento passado da economia e da taxa de câmbio real, a qual pode influenciar a composição

9 Esse efeito negativo do crescimento passado elevado para a elasticidade renda da demanda das exportações em Setterfield (1997) ocorre, pelo menos em uma economia madura, quando esta é bem sucedida no mercado internacional ao acompanhar a demanda dos seus produtos exportados. Para que isso ocorra de forma bem sucedida, essa economia continuamente adapta sua estrutura produtiva para esse mercado. Essa adaptação em um contexto de rápido crescimento pode ser difícil, uma vez que a estrutura produtiva pode sofrer de um efeito lock in (explicação na página 6), tornando-se pouco competitiva ou obsoleta, diminuindo $\varepsilon$. Essa formulação de Setterfield (1997) vem como uma forma de superação da crítica feita por ele em relação ao modelo de Dixon e Thirlwall (1975), o qual é na literatura econômica uma referência formal fundamental das ideias de Kaldor sobre o crescimento econômico. Para uma análise de uma nova extensão do modelo Dixon e Thirlwall (1975) com mudança estrutural e taxa de câmbio real em que a ideia de path dependence está presente veja Missio e Gabriel (2016). 
das exportações, bem como a própria estrutura produtiva). A partir dessa discussão, na seção 3 é apresentado como a razão das elasticidades do comércio internacional pode se tornar endógena à participação da indústria do Sul e ao hiato tecnológico.

\section{Mudança Estrutural e Crescimento Econômico de Longo Prazo}

Nicholas Kaldor argumentou em vários trabalhos ${ }^{10}$ que é impossível entender os processos de desenvolvimento e crescimento econômico sem se levar em conta uma abordagem setorial, distinguindo entre atividades de retornos crescentes daquelas atividades de retornos decrescentes. Os retornos crescentes de escala estão presentes na indústria, em especial no setor manufatureiro, enquanto que atividades primárias, como aquelas relacionadas à agricultura e mineração possuem retornos decrescentes.

Analisar o crescimento econômico no longo prazo requer aprofundar a compreensão de como a mudança estrutural ${ }^{11}$ se orienta para os setores que possuem maior capacidade de promover progresso tecnológico, de acompanhar ou direcionar as tendências da demanda de bens e serviços mais dinâmicos e de gerar maior produtividade. Portanto, a mudança da composição estrutural de uma economia de atividades econômicas de menores retornos de escala para atividades de maiores retornos tem importantes implicações, como aqueles relacionados aos efeitos de encadeamento para frente (forward linkages) e para trás (backward linkages) na cadeia produtiva (mais fortes na indústria), bem como os spillovers associados, ou seja, o fluxo de conhecimento e tecnologia.

${ }^{10}$ Veja, por exemplo, Kaldor (1957 e 1966).

${ }^{11}$ De uma maneira geral, o conceito de mudança estrutural pode ser definido como uma mudança na composição setorial do emprego ou do valor adicionado. 
Tendo em vista o que foi desenvolvido na seção 2, a razão das elasticidades no modelo canônico pode ser coloca em termos de Norte e Sul e em tempo contínuo. ${ }^{12}$ Desta forma, a taxa de crescimento do Sul em condições de equilíbrio no Balanço de Pagamentos e sem fluxo de capitais pode ser expressa como:

$\hat{y}_{s}=\left(\frac{\hat{\varepsilon}}{\hat{\pi}}\right) \hat{y}_{n}$ ou $\hat{y}_{s}=\left(\frac{\hat{x}}{\hat{\pi}}\right)$ em que $\left(\frac{\hat{\varepsilon}}{\hat{\pi}}\right)=f\left(h_{s}, G\right) \operatorname{com} f_{h_{s}}^{\prime}>0$ e $f_{G}^{\prime}<0$

De acordo com (2) a taxa de crescimento do Sul $\left(\hat{y}_{s}\right)$ depende da taxa de crescimento do Norte $\left(\hat{y}_{n}\right)$, da razão entre as elasticidades renda das exportações e importações do Sul ( $\hat{\varepsilon}$ e $\hat{\pi}$, respectivamente) e são endógenas à participação da indústria no produto doméstico $\left(h_{s}\right)$ e à distância tecnológica do Sul em relação à fronteira tecnológica $(G)$. O hiato tecnológico é um determinante importante da elasticidade renda das exportações e, portanto, também de acordo com os modelos de crescimento orientados pela demanda, da taxa de crescimento que é compatível com o equilíbrio do Balanço de Pagamentos (Dosi, Pavitt e Soete 1990).

Essa equação representa formalmente o fato estilizado de que um conjunto de países em desenvolvimento tem experimentado um rápido processo de crescimento e de catching up tecnológico associado à maior presença da indústria no produto e redução de assimetrias tecnológicas (Szirmai 2012). Em relação ao papel da indústria:

The historical evidence provides stronger support for the engine of growth thesis. This paper argues that there are no important examples of success in economic development in developing countries since 1950, which have not been driven by industrialisation. All the Asian success stories are stories of industrialisation. Neither tourism, nor primary exports, nor services have played a similar role, with the possible exception of software services in India since 2000. (Szirmai 2012, 417). - grifos adicionados.

$12 \mathrm{O}$ acento circunflexo representa a derivada de cada variável em relação ao tempo, ou seja, a taxa de crescimento de cada variável em relação a $t$ (tempo). Seja $y$ uma variável qualquer: $\hat{y}=\frac{d Y}{d t} \frac{1}{Y}$. O tempo considerado será o contínuo, tendo em vista que para vários problemas em economia é conveniente essa suposição, de forma que a evolução das variáveis dinâmicas seja ditada por equações diferenciais e seja possível usar um grande repertório do cálculo diferencial e integral. 
Ao partimos diretamente da razão das elasticidades estamos seguindo McCombie e Roberts (2002) e Setterfield (1997), dentre outros, uma vez que o objetivo deste modelo - assim como desses autores - não é evidenciar o efeito de causação cumulativa sobre o crescimento, mas sim o efeito da mudança estrutural, no sentido Kaldoriano, sobre a razão das elasticidades. Além disso, será formalizado o esforço que o Sul deve realizar em termos de $\mathrm{P} \& \mathrm{D}$, investimento em capital humano e capacidade de assimilação de spillovers para o seu sucesso no processo de catching up e convergência de renda em condições de equilíbrio no Balanço de Pagamentos. ${ }^{13}$

Por meio de (2) pode-se observar que o esforço do Sul para reduzir o hiato tecnológico influencia diretamente a sua trajetória de crescimento. Esse esforço pode ser mensurado a partir da capacidade de assimilação (capability to absorb) de conhecimento.

Devemos lembrar do modelo de Thirlwall (1979) que:

$$
\begin{aligned}
& \hat{x}=\eta\left(\hat{p}_{d}-\hat{p}_{f}-\hat{e}\right)+\varepsilon \hat{z} \\
& \hat{m}=\psi\left(\hat{p}_{f}+\hat{e}-\hat{p}_{d}\right)+\pi \hat{y}
\end{aligned}
$$

Em (3) $\hat{x}$ representa a taxa de crescimento das exportações, $\eta$ é a elasticidade preço da demanda por exportações, $\varepsilon$ a elasticidade renda das exportações, $\hat{z}$ a taxa de crescimento do mundo e $\left(\hat{p}_{d}-\hat{p}_{f}-\hat{e}\right)$ representa os termos reais de troca, em que $\hat{p}_{d}$ representa a taxa de crescimento dos preços domésticos, $\hat{p}_{f}$ é a taxa de crescimento dos preços estrangeiros e $\hat{e}$ a taxa de crescimento da taxa de câmbio nominal. Já em (4) $\widehat{m}$ representa a taxa de crescimento das importações, $\psi$ a elasticidade preço da demanda por importações, $\pi$ é a elasticidade renda da demanda por importações e $\hat{y}$ a taxa de crescimento da economia.

Assume-se que o Sul seja uma economia pequena do tipo export led e que sendo válida a paridade do poder de compra $\left(\hat{p}_{d}-\hat{p}_{f}-\hat{e}=0\right)$, sem fluxo de capitais, podemos simplificar (3) e (4):

$$
\begin{aligned}
& \hat{x}=\hat{\varepsilon} \hat{y}_{n} \text { em que } \hat{\varepsilon}=f\left(h_{s}, G\right) \operatorname{com} f_{h_{s}}^{\prime}>0 \text { e } f_{G}^{\prime}<0 \\
& \hat{m}=\hat{\pi} \hat{y}_{s} \text { em que } \hat{\pi}=f\left(h_{s}, G\right) \operatorname{com} f_{h_{s}}^{\prime}<0 \text { e } f_{G}^{\prime}>0
\end{aligned}
$$

13 Os efeitos do P\&D, capital humano e spillovers industriais sobre a competividade da indústria do Sul se darão formalmente por meio da redução da fronteira tecnológica, na seção 5 . 
Desta forma, para conhecermos a evolução dinâmica da taxa de crescimento em equilíbrio do Balanço de Pagamentos temos que analisar a evolução de $\hat{\varepsilon}$ e $\hat{\pi}$ (agora, em termos de suas taxas de crescimento). Nas equações acima, $\hat{y}_{n}$ representa a taxa de crescimento do Norte e $\hat{y}_{s}$ a taxa de crescimento do Sul.

Ao se assumir a PPC, as variações da taxa de câmbio real não são consideradas relevantes para o crescimento econômico, conforme o modelo canônico. Ao se assumir essa hipótese está se ignorando uma série de efeitos desta variável sobre a estrutura produtiva e o crescimento econômico de longo prazo.

A mudança estrutural da economia é dada a partir da Equação (7), a qual informa a taxa de variação da participação da indústria no PIB do Sul (em termos de valor adicionado):

$$
\hat{h}_{s}=\sigma\left(\theta-\theta_{i}\right)-\beta(G)-\psi h_{s} \operatorname{com} 0 \leq \sigma<1
$$

Em que:

$$
\theta_{i}=\frac{U L C_{s}}{P_{S}} / \frac{U L C_{n}}{P_{n}} \text { onde } n=\text { Norte e } s=\text { Sul }
$$

Onde: $\hat{h}_{s}$ é a taxa de variação da participação da indústria no PIB do Sul; $\theta$ é a taxa de câmbio real efetiva; $\theta_{i}$ é a taxa real de câmbio de equilíbrio industrial; $G$ é o hiato tecnológico; $\sigma$ é um parâmetro que representa as políticas discricionárias que tratam diretamente do desenvolvimento do setor industrial; $\beta$ é um coeficiente que capta a sensibilidade da estrutura produtiva ao hiato tecnológico; $\psi$ é o parâmetro que capta a influência da participação da indústria no Sul em termos de nível e $h_{s}$ representa o referido nível de participação da indústria nesta economia (em termos de valor adicionado). ${ }^{14}$

Quanto maior o nível do hiato tecnológico $(G)$, menor será $\hat{h}_{s}$, devido a fatores como a assimetria tecnológica, baixa competitividade extra preço, dentre outros fatores associados. O nível de hiato tecnológico é dado por

\footnotetext{
${ }^{14}$ Neste caso, quanto maior (menor) o nível de participação da indústria na economia do Sul, menor (maior) será a taxa de variação $\hat{h}_{s}$, ou seja, maior (menor) tenderá a ser o efeito do parâmetro $\psi$. Portanto, para níveis inicialmente baixos da participação da indústria na economia do Sul, maior tenderá a ser o efeito positivo da taxa de câmbio real (desvalorizada) sobre $\hat{h}_{s}$ para dado nível de hiato tecnológico.
} 
$G=\ln \left(\frac{I_{n}}{I_{S}}\right)$, em que $I_{n}$ representa as atividades inovativas do Norte e $I_{S}$ representa as atividades inovativas do Sul. ${ }^{15}$

Por meio da Equação (7) podemos perceber que se a economia do Sul estiver distante da fronteira tecnológica $(G>0)$, então a participação da indústria no produto só poderá aumentar ao longo do tempo se a taxa real de câmbio efetiva for maior do que o nível de equilíbrio industrial, ou seja, se a taxa real de câmbio estiver subvalorizada (depreciada). A ideia subjacente à Equação (7) é de que como as empresas do Sul estão operando abaixo da fronteira tecnológica e, portanto, em desvantagem do ponto de vista da competitividade extra preço, elas precisam compensar esta desvantagem com alguma vantagem de competitividade preço, a qual é representada aqui por meio de uma taxa de câmbio real efetiva superior à taxa de câmbio de equilíbrio industrial. De outra maneira, quanto maior o hiato tecnológico, mais competitivo terá de ser o Sul em termos de competitividade preço para manter a participação da indústria no produto constante $\left(\hat{h}_{s}=0\right)$.

Em (8) estamos seguindo Marconi (2012) e Oreiro (2016) para a definição da taxa de câmbio real de equilíbrio industrial, agora em termos de Norte e Sul. De acordo com essa expressão a taxa de câmbio real do Sul estará em seu nível satisfatório, ou seja, para preservar a competitividade de seus produtores de bens manufaturados no mercado internacional, quando for igual à razão entre os custos unitários do trabalho (ULC), em termos reais do Sul $(s)$, em relação ao Norte $(n)$. A participação da indústria no produto só poderá aumentar ao longo do tempo se a taxa real de câmbio estiver depreciada (subvalorizada) nos termos da Equação (8). Isso ocorre quando $\theta>\theta_{i}$.

A dinâmica da participação da indústria no produto do Sul impacta a elasticidade renda das exportações na medida em que redefine o padrão de especialização produtivo desta região em relação ao seu comércio com o Norte. Além disso, essa dinâmica afeta a própria composição da demanda no Sul a partir do efeito da Lei de Engel. Nesse sentido, na medida em que o crescimento do produto per capita aumenta, a estrutura do consumo

${ }^{15} \mathrm{Na}$ seção 5 a dinâmica do hiato tecnológico é formalmente desenvolvida. Essas atividades inovativas são aquelas que implicam mudança no conhecimento, habilidades e técnicas requeridas para a produção de bens industriais de maior valor agregado e qualidade. Essas atividades levarão em conta tanto o capital humano quanto o estoque de conhecimento. 
das famílias muda. Nesse caso, os gastos em bens agrícolas ou primários diminuem e crescem os gastos com os bens industrializados. ${ }^{16}$

O efeito composição neste modelo ocorrerá quando os bens industriais produzidos aumentarem (em termos de participação do produto doméstico) e possuírem maior conteúdo tecnológico, bem como maior competitividade preço (o nível da taxa de câmbio afeta os preços relativos dos bens tradeables e non tradeables, afetando a estrutura produtiva interna e sua competitividade externa). Portanto, nesse modelo, esse efeito refere-se à mudança das elasticidades provocada pela alteração na pauta de exportações do Sul no que diz respeito tanto à quantidade de bens que compõe essa pauta quanto à participação relativa de cada um deles (Ferrari et al. 2013).

Na próxima seção será apresentada a fundamentação teórica relacionada à importância do Sistema Nacional de Inovações sobre o processo de inovação e capacidade de assimilação de conhecimento (capability to absorb), as quais poderão permitir que o Sul possa reduzir o seu hiato tecnológico.

\section{As capacidades Absortivas Sociais e o Sistema Nacional de Inovação}

A partir de Narula (2004) pode-se observar que o crescimento econômico não se refere apenas à aquisição e desenvolvimento de conhecimento por meio da inovação e aprendizagem, mas também pela difusão e eficiente utilização do conhecimento.

Economias em desenvolvimento devem possuir a capacidade de internalizar e utilizar o conhecimento disponível. Essa habilidade é chamada de capacidade absortiva, o que, de acordo com Narula (2004), implica a oferta adequada de capital humano e capacitação tecnológica em nível macroeconômico que irá permitir o uso eficiente do conhecimento por parte das

\footnotetext{
${ }^{16}$ Bens industrializados tendem a ter uma elasticidade renda da demanda superior à unidade, conforme McCombie e Thirlwall (1994, p.389). Entretanto, há outro mecanismo pelo qual ocorrerá uma mudança da composição da demanda. Conforme poderá ser observado na seção 4 , o capital humano tem efeito positivo sobre as atividades de inovação da economia do Norte e Sul. Nesta última região, menos desenvolvida, a elevação do nível de capital humano irá impactar a demanda e a diversidade de novos produtos dessa economia - "efeito Stiglitz" e "efeito Schumpeter-Stiglitz", respectivamente.
} 
firmas. ${ }^{17}$ Somente desta maneira a economia pode melhorar em competitividade por meio do crescimento da produtividade.

A capacidade absortiva na literatura evolucionária tem sido extensivamente pesquisada ao nível da firma. Cohen e Levinthal $(1989,569)$ a definem como a habilidade da firma em identificar, assimilar e explorar conhecimento a partir do meio em que está inserida.

Em nível nacional a capacidade absortiva é definida como a habilidade que diferentes países possuem para aprender e implementar tecnologias e práticas associadas de países já desenvolvidos (Dahlman e Nelson 1995). Dessa forma, em nível agregado, a capacidade absortiva não é a simples agregação de setores econômicos e firmas. Há efeitos multiplicativos devido à interação micro e meso (e.g., agência públicas regionais de inovação) que acabam por ser significativos ao nível nacional e influenciam a trajetória e padrão de acumulação tecnológico (Narula 2004). ${ }^{18}$

Na tradição evolucionária, os sistemas nacionais de inovação (SI) são necessários para que o novo conhecimento e a inovação possam se difundir por toda a economia. Esses sistemas demandam a presença e interação de diferentes atores como empresas, instituições financeiras, universidades, instituições de pesquisa, recursos do setor público, dentre outras (Lundvall 1992 e Freeman 1995).

Quanto mais desenvolvido o SI, maior a capacidade de assimilação de conhecimento pelos países (capability to absorb). Entretanto, menor será sua capacidade de absorção (absorptive capacity), uma vez que esta é uma função do montante de conhecimento que ainda precisa ser assimilado.

${ }^{17}$ Em nível microeconômico, o desenvolvimento de conhecimento aplicado no sistema produtivo pode ser incremental ou radical. No caso do conhecimento incremental, as empresas industriais adquirem seu conhecimento por meio da exploração de ativos já existentes, como rotinas (routinized learning) ou processos por meio do chamado learning-by-doing. Quando esse conhecimento é adquirido por meio da interação com o ambiente externo das empresas industriais, quer seja por meio de relacionamento com os consumidores, fornecedores, competidores ou agências públicas, esse processo é chamado de learning-by-interacting. O conhecimento radical é desenvolvido a partir da aprendizagem não rotinizada, por meio de experimentações (exploratory learning) - Narula (2004). Outras possibilidades são os processos de learning-by-doing, learning-by-using, ou mesmo, learning-by-learning. Neste último caso, temos que quanto maior o nível de capital humano de uma economia, maior a possibilidade de aprendizagem da mão de obra empregada no sistema produtivo (cf. Verspagen 1993).

18 Para uma revisão completa sobre a dimensão conceitual da capacidade absortiva em nível microeconômico, ver Zahra e George (2002). Apesar da definição em nível macro fornecida por Dahlman e Nelson (1995) em relação à capacidade absortiva, há grandes dificuldades analíticas de defini-la, sendo considerada muitas das vezes uma "caixa preta" na literatura (Criscuolo e Narula 2008, 57). 
Quando o Sul absorve todo o conhecimento disponibilizado pelo Norte, a capacidade de absorção do Sul é nula, mas a capacidade de assimilação de novos conhecimentos é elevada (Narula 2004). ${ }^{19}$ Além disso, o sucesso das firmas em assimilar e desenvolver novos conhecimentos depende do próprio nível de amadurecimento deste sistema (Lundvall 1992, Freeman 1995).

A criação de conhecimento novo está quase sempre associada às atividades formais de P\&D que são realizadas de maneira sistemática nas instituições que compõem o SI como universidades, laboratórios e instalações públicas e privadas. A atividade de P\&D é considerada pela UNCTAD (2005) a forma mais avançada de atividade tecnológica nos países.

Nesse contexto, o SI está intimamente ligado com a estrutura produtiva e as elasticidades renda do comércio internacional. O nível de sofisticação da cadeia produtiva de um país é influenciado pelo SI de forma determinante. Existe um diferencial de competitividade (e, portanto, também nas elasticidades renda) entre economias especializadas em bens intensivos em tecnologia e as economias especializadas em bens com baixa intensidade tecnológica. ${ }^{20}$

A capacitação tecnológica e potencial de aprendizagem no SI é determinada, dentre os fatores mencionados, pelo capital humano das firmas e instituições. ${ }^{21}$ Tanto para o desenvolvimento de novas tecnologias, quanto para a imitação e internalização de spillovers são necessários indivíduos treinados e qualificados associados a outros fatores de produção em setores econômicos em que esses se façam necessários. Entretanto, vale ressaltar

19 O custo de imitação aumenta quando a economia menos desenvolvida (Sul) se aproxima da fronteira tecnológica e a quantidade de tecnologias potenciais para imitação se reduz. Isso implica, conforme Narula (2004), retornos marginais decrescentes na capacidade absortiva quando determinado país se aproxima desta fronteira. Para Criscuolo e Narula (2008), em nível nacional, a capacidade de absorção é uma função de três fatores: i) o gasto em P\&D; ii) do nível de desenvolvimento do Sistema Nacional de Inovações, o qual determina dentre outras coisas, a difusão do conhecimento nacionalmente e iii) do hiato tecnológico.

20 Sobre esse vínculo da estrutura produtiva com as elasticidades renda do comércio internacional tem-se que: "Moreover, different commodities and sectors are likely to be associated with different levels of opportunities for innovation and different income elasticities of demand. Hence, the national patterns of technological and production specialization may feedback on the long term dynamism of each economy". (Dosi, Freeman e Fabiani 1994, 16)

${ }^{21}$ No sentido amplo as instituições aqui referidas envolvem "(...) sets of common habits, routines, established practices, rules, or laws that regulate the relations and interactions between individuals and groups." (Edquist e Johnson 1997, 46, Cap. 2). Essa definição capta a essência do conceito clássico de North (1990) e a relaciona com o aprendizado advindo da interação entre as instituições e inovações, conforme Edquist e Johnson (idem). 
que esses setores, como o industrial, não se expandem somente devido à existência de mão obra qualificada.

Apesar do capital humano ser fundamental para a capacidade de aprendizagem, sua presença não é suficiente para a acumulação do estoque de conhecimento. Isso depende, além do desenvolvimento do SI, do uso eficiente dos mercados e hierarquias intra-firmas, intra-indústrias, intra-países, conforme Narula (2004). Em outros termos, o capital humano é condição necessária para o catching up, mas há a necessidade de incentivos apropriados para a expansão produtiva (como os investimentos) que esse recurso, juntamente com o SI, pode fornecer. Dessa maneira, o processo de catching up do Sul dependerá da ação combinada das capacitações, incentivos e instituições.

Quanto mais desenvolvido for o SI do Sul, maior será a possibilidade de se avançar em direção à fronteira tecnológica dos diversos setores de produção da economia. Nesse sentido, maior tenderá a ser o grau de diversificação de sua base produtiva. Essa diversificação, atrelada ao maior conteúdo tecnológico, implicará uma maior (menor) elasticidade renda da exportação (importação).

Evidencia-se, portanto, que o desenvolvimento do SI possibilita maior sofisticação tecnológica à estrutura produtiva, o que reflete em mudanças nas elasticidades renda do comércio internacional (maior elasticidade renda da demanda por exportações e menor elasticidade renda da demanda por importações) e, por conseguinte, aumento da taxa de crescimento econômico compatível com o equilíbrio no Balanço de Pagamentos. Em outras palavras, é a intensidade tecnológica dos produtos comercializados que sustentará o resultado comercial positivo ao longo do tempo.

O sucesso da difusão e internalização das inovações tecnológicas em termos de aumento da produtividade é condicional à articulação das capacitações sociais, de uma estrutura tecnológica mínima pré-existente (Abramovitz 1986) e de suas capacidades absortivas (Cohen e Levinthal 1989). O arranjo sistêmico destes fatores afeta o nível de desenvolvimento do SI.

No que diz respeito às capacitações sociais Abramovitz $(1986,389)$ aponta que estas dependem do nível educacional dos trabalhadores e dos tipos de organizações existentes. Além disso, fatores como abertura do país para a competição internacional, para o estabelecimento e operação de novas 
empresas, bem como para compra e venda de novos produtos também fazem parte destas capacitações. Esse conceito de capacidade social é muito similar ao conceito de capacidade absortiva em nível nacional de Dahlman e Nelson (1995) e Narula (2004).

Conforme pudemos observar acima, quanto mais desenvolvido o SI, maior a capacidade de assimilação de conhecimento pelos países (capability to absorb). No presente artigo, essa capacidade de assimilação de conhecimento será uma função do capital humano e do estoque de conhecimento do Sul e do Norte, sendo elementos formalmente modelados na seção 5 para explicarem tanto o processo de inovação ao longo do tempo como a própria capacidade de assimilação de conhecimento, uma vez que o avanço tecnológico sustentará maiores níveis de dessa capacidade durante o processo de catching up

Conforme poderá ser observado na seção 5, o estoque de conhecimento do Sul será uma função endógena da dinâmica das atividades de inovação (as quais dependem do capital humano desta região), da capacidade de assimilação de spillovers e do nível de desenvolvimento do SI. Para que esse estoque de conhecimento seja efetivamente utilizado pelo Sul (economia menos desenvolvida) o determinante primário da acumulação tecnológica será o capital humano. Nesse caso, o capital humano envolve:

(...) the competence to evaluate and utilize outside knowledge is largely a function of the level of prior related knowledge. Qualified human resources are essential in monitoring the evolution of external knowledge and in evaluating their relevance, and for the integration of these technologies into productive activities" Criscuolo e Narula $(2008,59)$ - Grifos adicionados.

Dessa forma, tanto a acumulação de capital humano quanto de capital físico são condições necessárias para a ocorrência do catching up do Sul e a indústria é o setor tradeable fundamental, em que o estoque de conhecimento de uma determinada economia se acumula com mais dinamismo. 
Tanto o capital físico quanto o capital humano são necessários para expandir a participação da indústria na economia do Sul, uma vez que ambos afetam o hiato tecnológico. Entretanto, eles não serão utilizados efetivamente se os incentivos para o investimento e produção forem inapropriados. Do ponto de vista do presente modelo, esse incentivo será dado pela diferença entre a taxa de câmbio real efetiva e seu nível de equilíbrio industrial (definida na seção 3). Quanto maior esse diferencial, maiores serão os incentivos em termos de competitividade preço para a expansão da indústria na economia do Sul. Em relação às capacitações necessárias e às instituições, o processo de catching up dependerá fundamentalmente do nível de desenvolvimento do SI (na seção 5 o mesmo é colocado explicitamente no modelo).

\section{A Dinâmica das Atividades de Inovação e do Estoque de Conheci- mento}

Na seção 4 vimos que quanto mais desenvolvido for o SI do Sul, maior será a possibilidade de se avançar em direção à fronteira tecnológica. Nesse sentido, maior tenderá a ser o grau de diversificação de sua base produtiva, tendo em vista o aumento da capacidade de assimilação do conhecimento existente bem como a geração de novos conhecimentos por meio das atividades inovativas. Neste artigo são utilizadas as formulações de Castellacci (2002) e Verspagen (1993) para a explicação da dinâmica das atividades de inovação da economia e do estoque de conhecimento, respectivamente. É possível observar que esses processos influenciarão a taxa de crescimento do Sul, consistente com o equilíbrio do Balanço de Pagamentos ao influenciarem $\widehat{G}$, cuja dinâmica é definida a seguir.

Os estoques de conhecimento do Norte e Sul são, respectivamente, dados por: ${ }^{22}$

$$
\begin{aligned}
& \widehat{T}_{n}=\zeta \hat{I}_{n} \text { com } \zeta>0 \\
& \widehat{T}_{s}=\zeta \hat{I}_{s}+S G e^{-\frac{G}{S I}} \text { com } \zeta>0, S \cdot G>0 \text { e } S I>0
\end{aligned}
$$

\footnotetext{
${ }^{22}$ Frisamos que cada variável com circunflexo representa a sua taxa de variação ao longo do tempo. Portanto, evitaremos ao longo do texto a repetição sistemática do termo "taxa de variação", salvo quando for estritamente necessário.
} 
Nestas equações, o parâmetro $\zeta$ captura a sensibilidade das atividades inovativas nas economias $\left(\hat{I}_{n}\right.$ e $\left.\hat{I}_{s}\right)$ sobre o estoque de conhecimento $\left(\hat{T}_{n}\right.$ e $\left.\hat{T}_{s}\right)$. Em particular, na Equação (10), é possível observar que o Sul pode explorar o maior estoque de conhecimento do Norte, seja por meio do processo de imitação ou de assimilação de spillovers tecnológicos (dado por $S \cdot G$ ), onde $S=d h_{s}$ em que o parâmetro $d>0$ representa os spillovers da indústria na economia, sejam eles intraindustriais ou interindustriais e $h_{s}$ o nível de participação da indústria no Sul. Entretanto, o processo de assimilação destes spillovers depende do nível de desenvolvimento do SI em relação à magnitude do hiato tecnológico $\left(e^{-\frac{G}{S I}}\right) .{ }^{23}$

Por meio da Equação (9), observa-se que a única fonte de crescimento do estoque de conhecimento do Norte, região que se situa na fronteira do conhecimento, é a partir de suas atividades de inovação realizadas internamente $\left(\hat{I}_{n}\right)$. Dessa forma, não está se incorporando qualquer possibilidade de assimilação de spillovers tecnológicos do Sul para o Norte.

De acordo com Cohen e Levinthal (1989 e 1990), as atividades de P\&D são as bases de criação de novos conhecimentos realizados nas universidades e organizações públicas de pesquisas, bem como em firmas que elevam o estoque de conhecimento e o nível de desenvolvimento do SI. Quanto maior o nível de investimento em $\mathrm{P} \& \mathrm{D}$, maior será o grau de desenvolvimento do SI para dado nível de $G$.

O processo de catching up do Sul não ocorre pela simples existência de G; há a necessidade da ação do Estado e iniciativa privada que permitam assimilar e aplicar o conhecimento existente nos processos produtivos. Formalmente, este argumento é captado pelo parâmetro SI.

As atividades inovativas do Norte e do Sul são dadas, respectivamente, pelas seguintes funções:

$$
\begin{aligned}
& \hat{I}_{n}=a H_{n}+b \widehat{T}_{n} \quad \text { com } a>0 \text { e } b>0 \\
& \hat{I}_{s}=a H_{s}+b \hat{T}_{s} \quad \text { com } a>0 \text { e } b>0
\end{aligned}
$$

${ }^{23}$ Frisamos que na Equação (10) SI se refere ao Sistema Nacional de Inovações e SG implica S multiplicado por $G$. 
Onde: $H$ representa o estoque de capital humano e $T$ o estoque de conhecimento, para o $n$ (Norte) e o $s$ (Sul), conforme definidos anteriormente e $a$ e $b$ são parâmetros associados a $H$ e $T$, respectivamente.

As atividades de inovação do Sul contribuem para reduzir as assimetrias tecnológicas, bem como para aumentar a capacidade de assimilação de conhecimento desta região. Dessa forma, o hiato tecnológico poderá ser reduzido, contribuindo assim para o aumento da participação da indústria no produto do Sul. Essa mudança estrutural levará a um aumento da razão das elasticidades de comércio internacional, viabilizando um aumento da taxa de crescimento do Sul que é compatível com o equilíbrio no Balanço de Pagamentos.

Por meio das Equações (11) e (12), podemos considerar dois novos possíveis canais de influência do capital humano sobre o crescimento da indústria: ${ }^{24}$

i) Um maior estoque de capital humano implica maior demanda por produtos diferenciados industriais, uma vez que há uma relação positiva entre o nível educacional das pessoas e a demanda de bens diferenciados: originalmente esse efeito é o chamado "efeito Stiglitz". ${ }^{25}$ Produtos diferenciados implicam em uma estrutura produtiva mais diversificada e sofisticada. No modelo proposto, $H_{s}$ afetará positivamente $\hat{I}_{s}$, da mesma maneira, afetará positivamente $\widehat{T}_{s}$, o que ceteris paribus, diminuirá o hiato tecnológico $(G)$, afetando positivamente a participação da indústria na economia do Sul $\left(h_{s}\right)$, ou seja, o efeito da Lei de Engel é reforçado

${ }^{24}$ Essas hipóteses são exploradas de maneira não formalizada por Welfens (2010) ao analisar o trabalho de Gould e Ruffin (1995) em um modelo teórico da "nova" teoria do crescimento endógeno. Em linhas gerais, o trabalho de Gould e Ruffin (1995) separa os efeitos do capital humano sobre a produção e como determinante do progresso tecnológico e crescimento de longo prazo. Originalmente, os autores discutem como a abertura comercial afeta o crescimento. Empiricamente, Gould e Ruffin (1995) encontram resultados que sugerem que o capital humano, para a amostra de economias pesquisadas, possui mais efeitos em uma economia aberta do que em uma economia fechada. Entretanto, não encontram uma explicação satisfatória para isso, a qual é dada por Welfens (2010) ao analisar o trabalho destes autores. Entretanto, como já destacado, Welfens (2010) não formaliza suas hipóteses a respeito destes canais e não explica qual o papel do capital humano no processo de inovação.

${ }^{25}$ A referência original a Stiglitz decorre do resultado pioneiro encontrado por este autor quando se utiliza de um tipo específico de função utilidade em seus modelos, como em Stiglitz (1993). Neste artigo, o autor utiliza uma função utilidade com um número finito de mercadoria " $n$ " em condições CES (Constant Elasticity of Substitution). Com uma função utilidade deste tipo, Welfens $(2010,10)$ destaca que a acumulação de capital humano aumentará o número de variedades produzidas, o que significa que o número adicional de novas variedades excederá o número de mercadorias produzidas inicialmente. 
pela acumulação de capital humano no Sul. ${ }^{26}$ Neste caso, o efeito do capital humano sobre as atividades inovativas do Sul é eminentemente demand pull. ${ }^{27}$ Entretanto, conforme podemos observar no modelo, os fatores technology push, a partir das atividades de P\&D e do SI, são igualmente importantes para a redução do hiato tecnológico. ${ }^{28}$

ii) Em um cenário em que o estoque de capital humano no Sul se eleva, contribuindo para a diminuição do hiato tecnológico, as empresas poderão responder às maiores demandas por diversificação com novos produtos. Desta forma, $h_{s}$ poderá aumentar ao longo do tempo reforçando o processo de inovação e lançamento de novos produtos. Esse processo poderá reforçar as inovações por meio do lançamento de novos bens para atender essa demanda. Nesse contexto, haverá novas oportunidades para explorar economias de escala no setor industrial com esses novos lançamentos. Esse é o efeito "Schumpeter-Stiglitz", uma vez que conforme Schumpeter $(1997,76)$ atende o primeiro conceito clássico de inovação, ou seja, por meio de um novo produto ou da melhor qualidade de um produto já existente. Desta forma, é um processo cuja dinâmica possui mais características de technology push.

\section{Dessa forma, existe uma relação de interdependência entre as funções} de inovação tecnológica entre as duas economias e o estoque de conhecimento. Portanto, não são processos que ocorrem de forma independente no modelo, porque a capacidade de assimilação de spillovers depende do

${ }^{26} \mathrm{O}$ mesmo efeito pode ser observado por meio das equações do Norte. Entretanto, focaremos nossa análise na região Sul, em que serão analisadas as condições para o processo de catching up e convergência de renda em condições de equilíbrio no Balanço de Pagamentos. A melhoria do capital humano, ao afetar positivamente a produção industrial do Sul, melhora a razão das elasticidades do comércio internacional desta região, relaxando a restrição externa ao crescimento. Além disso, a maior demanda de bens industriais advinda do "efeito Stiglitz" pode ser atendida a partir da maior oferta de produtos do Sul.

${ }^{27} \mathrm{Ou}$ seja, oriundo de novas demandas de mercado e de grupos de consumidores, de acordo com a definição ampla de demanda por produtos "inovadores" de Godin e Lane $(2013,31)$.

${ }^{28}$ De acordo com Mowery e Rosenberg $(1979,143)$ sobre a inovação ser demand-pull ou technology-push estes autores nos colocam que os dois mecanismos são "(...) necessary, but not sufficient, for innovation to result; both must exist simultaneously". Mowery e Rosenberg (idem), assim como Freeman e Soete (2008) apresentam que a chance de sucesso de uma inovação ser bem sucedida é maior a partir desta interdependência de fatores. Além disso, durante as décadas que a abordagem demand pull foi dominante, Mowery e Rosenberg (1979) afirmaram criticamente que "the "demand-pull" approach simply ignores, or denies, the operation of a complex and diverse set of supply side mechanisms which are continually altering the structure of production costs" (Mowery e Rosenberg 1979, 143). Para uma análise histórica do processo de inovação a partir de estímulos demand pull, technology push, as origens do modelo linear de inovação, a ideia de paradigmas tecnológicos e outras referências para explicar o processo de inovação (e.g. coupling model, modelo integrado, System Integration and Networking - SIN - models), veja Godin e Lane (2013). 
nível de desenvolvimento de $S I$ e, ao mesmo tempo, da acumulação de conhecimento determinada por $\widehat{T}_{s} .{ }^{29}$

Como o nível de hiato tecnológico foi definido como $G=\ln \left(\frac{I_{n}}{I_{s}}\right)$, em que $I_{n}$ representa as atividades inovativas do Norte e $I_{S}$ representa as atividades inovativas do Sul, se segue que sua dinâmica ao longo do tempo é obtida pela derivada desta expressão em relação ao tempo, de forma que, $\widehat{G}=\left(\hat{I}_{n}-\hat{I}_{s}\right)$. Com base na manipulação das Equações (9), (10), (11) e (12), podemos chegar a:

$$
\widehat{G}=\left(\hat{I}_{n}-\hat{I}_{s}\right)=\frac{1}{1-b \zeta}\left[a\left(H_{n}-H_{S}\right)-b S G e^{-\frac{G}{S I}}\right] \operatorname{com} 0<b \zeta<1
$$

A Equação (13) fornece a dinâmica do hiato tecnológico ao longo do tempo, $\hat{G}$. Pode-se observar que, quanto menor a diferença no estoque de capital humano e quanto maior a capacidade do Sul de explorar o maior estoque de conhecimento do Norte, seja por meio do processo de imitação ou de assimilação de spillovers tecnológicos $(S)$, menor tende a ser a diferença entre as atividades inovativas do Norte e do Sul e, portanto, menor tende a ser o hiato tecnológico ao longo do tempo $(\widehat{G})$. Além disso, o maior desenvolvimento de $S I$ em relação a $G$ possibilitará maior sofisticação tecnológica da estrutura produtiva, o que também reduzirá o hiato tecnológico do Sul, de acordo com a equação acima.

Um resultado importante derivado da estrutura formal deste modelo é que a diferença entre as atividades inovativas entre Norte e Sul na Equação (13) pode ser também um indicador indireto do nível de complexidade do conhecimento que foi desenvolvido (e adquirido) pelo Sul, ou seja, do conhecimento explorado no SI e na produção de bens tradeables.

Aqui pode ser observada uma importante conexão com a abordagem inaugurada por Hausmann e Hidalgo et al. (2011) sobre o nível de complexidade de diferentes economias. De acordo com eles os produtos gerados nos sistemas econômicos podem ser vistos como feitos "com conhecimento", 30

${ }^{29}$ Essa simultaneidade na determinação do estoque de conhecimento e os processos de inovação também estão presentes na literatura evolucionária, como em Caniëls e Verspagen (2001), Criscuolo e Narula (2008) e Castellacci (2002), dentre outros. Entretanto, não são explorados de forma explícita os efeitos do capital humano e do grau de desenvolvimento do Sistema Nacional de Inovações em relação ao hiato tecnológico de maneira formal.

${ }^{30}$ Conhecimento explícito e tácito, sendo que este último é o mais difícil de ser adquirido em um processo de catching up tecnológico, apresentando-se como uma das principais restrições ao crescimento 
ou seja, "(...) products are vehicles for knowledge, but embedding knowledge in products requires people who possess a working understanding of that knowledge." (Hausmann e Hidalgo et. al. 2011, 15).

Esse montante de conhecimento em cada produto não depende, de acordo com os autores, exclusivamente do conhecimento individual, mas sim da diversidade de conhecimento entre os indivíduos especializados e livres para dividir a combinação que se fizer necessária destes conhecimentos a partir de uma teia complexa de interações. A produção do bem requer as capacitações nas organizações empresariais, as quais são capazes de selecionar o conhecimento relevante para cada manufatura.

A partir deste contexto, Hausmann e Hidalgo et al. (2011) definem a complexidade de uma economia como a multiplicidade de conhecimento útil incrustado no sistema econômico. Dessa forma:

"For a complex society to exist, and to sustain itself, people who know about design, marketing, finance, technology, human resource management, operations and trade law must be able to interact and combine their knowledge to make products. These same products cannot be made in societies that are missing parts of this capability set. Economic complexity, therefore, is expressed in the composition of a country's productive output and reflects the structures that emerge to hold and combine knowledge." Hausmann e Hidalgo et al. $(2011,18)-$ grifos adicionados.

Com essas definições da abordagem inaugurada por Hausmann e Hidalgo et al. (2011), reafirma-se, a partir de outra metodologia/abordagem (ou seja, do nível da complexidade econômica), que, apesar de o capital humano ser fundamental para a capacidade de aprendizagem, não se chega a uma condição suficiente para a acumulação do estoque de conhecimento, sendo que no caso desses autores, o maior empecilho para produtos mais complexos seria a ausência de um conjunto de capacitações, redes de interações entre instituições e organizações enquanto que na abordagem (evo-

dos países. Hausmann e Hidalgo et al. (2011) referem-se a esse conhecimento como capacitações. Essas capacitações podem estar relacionadas diretamente aos indivíduos, organizações ou em redes de empresas. 
lucionária) de Narula (2004), Criscuolo e Narula (2008), dentre outros, a barreira para isso seria o nível de desenvolvimento do SI, do uso eficiente dos mercados e hierarquias intra-firmas, intra-industrias, intra-países. ${ }^{31}$

No presente modelo, quanto mais próxima da fronteira tecnológica o Sul se encontrar, maior o nível de complexidade da estrutura produtiva nos termos de Hausmann e Hidalgo et. al. (2011). Além disso, quanto mais próximo desta fronteira, maior deverá ser o esforço inovativo por meio do desenvolvimento do $S I$ do Sul (para dado nível de $G$ e $H_{S}$ ).

Na Figura 1 (no apêndice A) podemos observar esquematicamente a conexão do modelo com a fundamentação de complexidade econômica delineada nesta seção.

Definidas formalmente as funções das atividades de inovação e do estoque de conhecimento que conformam a dinâmica do hiato tecnológico (seção 5) e como ocorre a mudança estrutural no modelo (seção 3), devemos realizar agora a análise de estabilidade de longo prazo do sistema de equações dinâmicas.

\section{Análise de Estabilidade de Longo Prazo e Convergência versus Divergência}

Para a análise da estabilidade de longo prazo, temos que partir do seguinte sistema dinâmico de equações do modelo:

$$
\grave{h}_{s}=\sigma\left(\theta-\theta_{i}\right)-\beta(G)-\psi h_{s}
$$

31 De acordo com Hausmann e Hidalgo et al. $(2011,18)$ "Complex economies are those that can weave vast quantities of relevant knowledge together, across large networks of people, to generate a diverse mix of knowledge-intensive products. Simpler economies, in contrast, have a narrow base of productive knowledge and produce fewer and simpler products, which require smaller webs of interaction. Increased economic complexity is necessary for a society to be able to hold and use a larger amount of productive knowledge, and we can measure it from the mix of products that countries are able to make". Esses autores explicam o desenvolvimento econômico como um processo de aprendizagem de como produzir (e exportar) produtos mais complexos. Nesse contexto, o desenvolvimento é determinado pela capacidade de acumular capacitações que são necessárias para produzir uma maior variedade de produtos mais complexos. Assim, o nível de complexidade econômica da estrutura produtiva de um país é a principal variável explicativa em relação ao seu crescimento e desenvolvimento econômico. 


$$
\widehat{G}=\frac{1}{1-b \zeta}\left[a\left(H_{n}-H_{s}\right)-b S G e^{-\frac{G}{S I}}\right]
$$

A dinâmica do sistema, a ser representado por um diagrama de fases, é dada por $h_{s}$ e $G$, desta forma, é necessário fazer $\hat{h}_{s}=0$ e encontrarmos $G$ em steady state:

$$
G^{*}=\frac{\sigma}{\beta}\left(\theta-\theta_{i}\right)-\frac{\psi}{\beta} h_{s}
$$

Neste equilíbrio de steady state (14) para que não ocorram mudanças da participação da indústria na economia do Sul o efeito negativo do hiato tecnológico sobre a economia do Sul para um dado nível de participação da indústria $\left(-\frac{\psi}{\beta} h_{s}\right)$ deve ser compensando por uma taxa de câmbio real efetiva depreciaada em relação ao seu nível de equilíbrio industrial. Do contrário, hiatos tecnológicos baixos estarão associados às taxas de câmbio menos depreciadas em termos reais. Isso significa que o processo de catching up pode reduzir a necessidade da utilização de políticas cambiais que visem a manter a taxa de câmbio real efetiva depreciada em relação ao nível da taxa de equilíbrio industrial.

De (13), fazendo $\widehat{G}=0$, tem-se que $a(H n-H s)=b \mathrm{dh}_{\text {s. }} G e^{-} G^{\prime} S I$ e, portanto, chega-se a seguinte expressão de steady state para a indústria do Sul:

$$
h_{s}^{*}=\frac{a\left(H_{n}-H_{s}\right)}{b d G e^{-\frac{G}{S I}}}
$$

De acordo com (15) para um determinado nível constante de hiato tecnológico, o nível de desenvolvimento do SI, bem como o produto do nível de assimilação dos spillovers em relação ao efeito do estoque de conhecimento sobre as atividades inovativas dos Sul, devem estar em tal magnitude que compensem as diferenças de capital humano entre as duas regiões.

Para analisar a estabilidade local do sistema formado pelas Equações (7) e (13) iremos linearizá-lo no entorno da sua posição de equilíbrio de longo-prazo por meio do primeiro termo da expansão de Taylor:

$$
\begin{aligned}
& \hat{h}_{s}=-\psi\left(h_{s}-h_{S}^{*}\right)-\beta\left(G-G^{*}\right) \\
& \widehat{G}=-\frac{1}{1-b \zeta} b d G e^{-\frac{G}{S I}}\left(h_{S}-h_{S}^{*}\right)-\frac{b d h_{S}}{1-b \zeta} e^{-\frac{G}{S I}}\left(1-\frac{G}{S I}\right)\left(G-G^{*}\right)
\end{aligned}
$$


Na sua forma matricial, o sistema $2 \times 2$ de equações fica:

$$
\left[\begin{array}{c}
\hat{h}_{S} \\
\hat{G}
\end{array}\right]=\left[\begin{array}{cc}
-\psi & -\beta \\
-\frac{1}{1-b \zeta} b d G e^{-\frac{G}{S I}} & -\frac{b d h_{S}}{1-b \zeta} e^{-\frac{G}{S I}}\left(1-\frac{G}{S I}\right)
\end{array}\right]\left[\begin{array}{c}
h_{S}-h_{S}^{*} \\
G-G^{*}
\end{array}\right]
$$

Em (18) podemos constatar que $-\frac{b d h_{s}}{1-b \zeta} e^{-\frac{G}{S I}}\left(1-\frac{G}{S I}\right)$ pode assumir um sinal positivo ou negativo. Portanto, serão analisadas duas situações de equilíbrio. No primeiro caso, pode-se constatar que o traço da matriz Jacobiana é negativo se $S I>G e b \zeta<1$, uma situação em que o Sul está realizando um esforço para o seu catching up. ${ }^{32}$ O Traço $|J|$ é negativo e igual a: $-\psi-\frac{b d h_{S}}{1-b \zeta} e^{-\frac{G}{S I}}\left(1-\frac{G}{S I}\right)$.

O determinante da matriz Jacobiana é igual a:

$$
\psi \frac{b d h_{s}}{1-b \zeta} e^{-\frac{G}{S I}}\left(1-\frac{G}{S I}\right)-\beta \frac{1}{1-b \zeta} b d G e^{-\frac{G}{S I}}
$$

Analisando-se o determinando pode-se constatar que Det $|J|>0$, se $\psi \frac{b d h_{S}}{1-b \zeta} e^{-\frac{G}{S I}}\left(1-\frac{G}{S I}\right)>\beta \frac{1}{1-b \zeta} b d G e^{-\frac{G}{S I}}$. Assim como no caso anterior, $S I>G$, ou seja, o Sul está realizando políticas para que o ocorra o desenvolvimento do seu Sistema Nacional de Inovação, para um dado nível de G e, assim, seu processo de catching up possa ocorrer. Nesse caso, está se considerando que o produto do efeito dos spillovers da indústria na economia do Sul para um dado nível de $\psi$ seja superior ao efeito negativo de um determinado nível de hiato tecnológico $\beta$.

Na situação acima, ou seja, com Traço $|J|<0$ e Determinante $|J|>0$, temos um equilíbrio assintoticamente estável. A segunda possibilidade de equilíbrio neste sistema dinâmico seria no caso em que $S I<G$, ou seja, o esforço do Sul em termos do desenvolvimento do seu Sistema Nacional

\footnotetext{
32 Se o produto da relação entre a influência do estoque de conhecimento $b$ sobre as atividades inovativas em relação a $\zeta$ - o qual captura a influência destas atividades sobre este estoque - estiver próximo de 0 ; então menor será a relação entre $I$ (atividades inovativas) e $T$ (estoque de conhecimento). Ao passo que quanto maior o produto dessa relação (mas menor do que 1), maior é o esforço da economia do Sul para fortalecer a relação existente entre o setor produtivo e o Sistema Nacional de Inovações (situação de catching up). Caso $b \zeta>1$ fosse possível, o comportamento do modelo seria explosivo.
} 
de Inovação é inferior ao nível de hiato tecnológico. Neste caso, conforme podemos ver em (18), o Determinante $|J|<0$ fazendo com que o sistema dinâmico seja instável.

Podemos ver esses dois equilíbrios na Figura 2. No ponto "A" temos o equilíbrio estável e no ponto "B" o equilíbrio instável, o qual não será explorado.

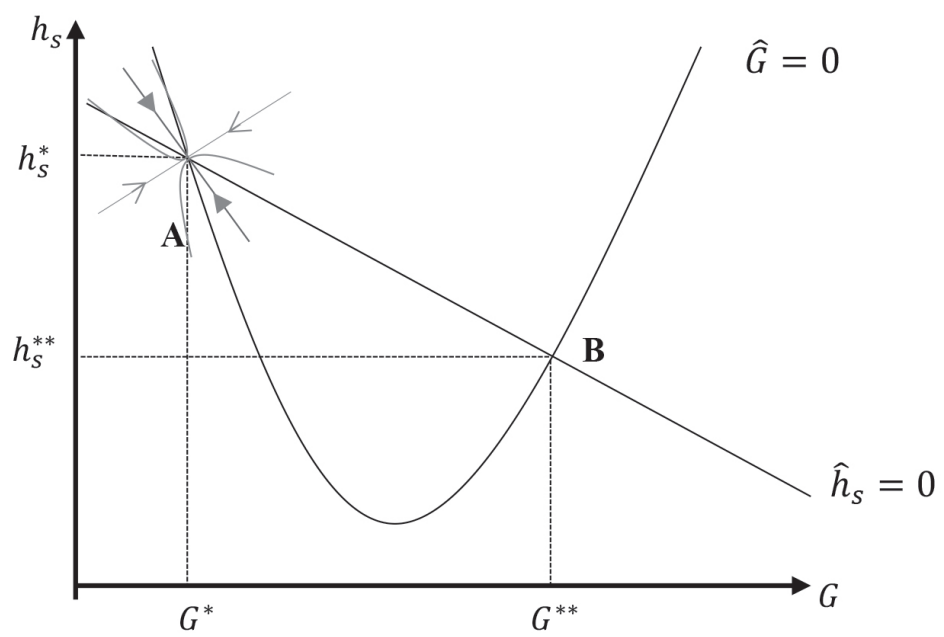

Figura 2 - Diagrama de fases da dinâmica de $\widehat{\boldsymbol{h}}_{\boldsymbol{s}}$ e $\widehat{\boldsymbol{G}}$ - A (estável) e B (instável) Fonte: Elaboração própria.

Em seguida, procederemos à análise de possibilidades de convergência ou divergência de longo prazo, considerando-se a possibilidade de catching up tecnológico e a restrição externa ao crescimento.

Seguindo Cimoli, Porcile e Rovira (2010), assume-se que as taxas de crescimento populacionais sejam similares entre Norte e Sul, de maneira que uma taxa maior de crescimento da renda do Sul enseje a convergência ao nível de renda verificada no Norte. Como a participação da indústria na economia do Sul e o hiato tecnológico se tornaram endógenos para explicar a dinâmica da razão das elasticidades renda das exportações e importações, a análise da Figura 3 será feita em termos de convergência de renda e catching up tecnológico em um contexto de restrição externa ao 
crescimento. ${ }^{33}$ A dinâmica da Figura 3 é decorrência direta da formulação observada em (2).

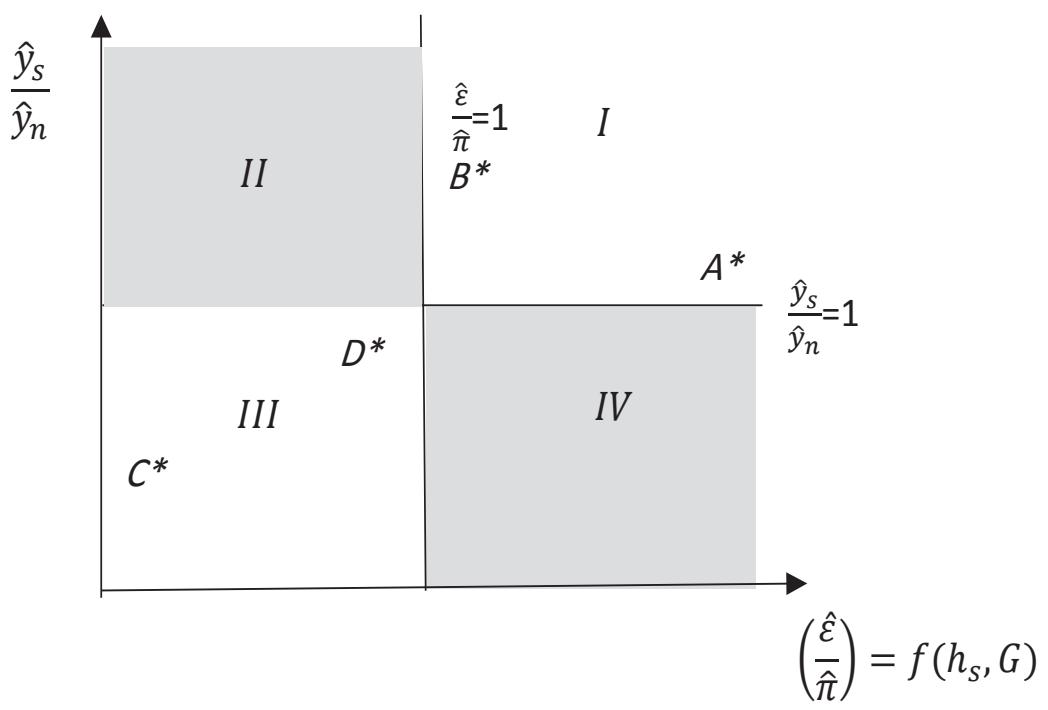

Figura 3 - Convergência ou Divergência de Renda e Tecnologia da Região Sul - "Forging ahead" ou "Falling Behind" ?

Fonte: Elaboração própria.

Podem ser observadas 2 regiões (quadrantes I e III) na Figura 3, as quais representam duas possíveis situações em decorrência da estrutura do modelo: ${ }^{34}$

I - Nesta região/quadrante pode ser verificada tanto uma convergência sustentável de renda quanto de catching up tecnológico. Para que essa situação de forging ahead se verifique, há duas possibilidades de política econômica que não são mutuamente excludentes: i) incentivo de

${ }^{33}$ Cimoli et. al. (2009) fazem uma análise em termos de convergência sustentável (conta corrente>0) e insustentável (conta corrente $<0$ ) da renda de uma determinada economia. No presente trabalho estão sendo incorporados em um modelo de restrição externa os efeitos simultâneos do hiato tecnológico e da mudança estrutural, mas com a conta de capitais fechada.

${ }^{34}$ Vale notar que os demais quadrantes (em cinza) não são condizentes com a função apresentada em (2), de forma que são analisados apenas os quadrantes I e III. Os quadrantes II e IV só seriam possíveis por meio da modelagem do efeito da poupança externa sobre o crescimento Sul. Somente neste caso que $\frac{y_{s}}{y_{n}}>1$, em um contexto de $\frac{\varepsilon}{\pi}<1$ ou seja, em uma situação de restrição externa ao crescimento, ou $\frac{y_{s}}{y_{n}}<1$, em um contexto de $\frac{\varepsilon}{\pi}>1$. Neste último caso, a mudança estrutural e a redução do hiato tecnológico não implicam em convergência de renda, em desacordo com a função (2). 
mudança estrutural com maior participação da indústria na economia com seus efeitos dinâmicos sobre os demais setores econômicos com a taxa de câmbio real efetiva depreciada em relação ao seu nível de equilíbrio industrial e ii) maior investimento em capital humano e maior desenvolvimento do Sistema Nacional de Inovação, o qual reduz o hiato tecnológico e também possui papel fundamental sobre o setor industrial do Sul, principalmente sobre a sua competitividade no preço. Nos dois casos haverá uma situação de "forging ahead", mas caso a escolha dos policy makers seja de incentivar a maior participação da indústria no Sul de maneira mais rápida do que se concentrarem na redução do hiato tecnológico, isso significa que deverão existir políticas que garantam taxas reais de câmbio cada vez mais depreciadas em relação ao seu nível de equilíbrio industrial. Já no caso em que a escolha seja o de maior desenvolvimento do SI em detrimento do crescimento mais rápido da participação da indústria no Sul, o Estado e os agentes econômicos devem assumir uma política mais robusta em termos de esforços inovativos na economia, reduzindo a necessidade de utilização da taxa de câmbio real como política econômica fundamental neste cenário.

III - Nesta região/quadrante o Sul está em uma situação de " $\mathrm{fal}$ ling behind", tanto em termos de renda quanto em termos tecnológicos, de forma que a mudança estrutural é regressiva e há restrição externa ao crescimento. Somente com políticas econômicas de investimento em inovação, melhoria do capital humano, desenvolvimento do SI e esforço inovativo é que o Sul poderá sair dessa região/quadrante para a região/quadrante I. Neste caso, as políticas cambiais e de inovação são fundamentais para melhorar a competividade preço e extra preço do setor industrial, respectivamente.

Por fim, vale ressaltar que tanto na região do quadrante I ("forging ahead") quanto na região do quadrante III ("falling behind"), são possíveis várias combinações relacionadas à convergência/divergência de renda e catching up/lagging behind tecnológico. Na Figura 3, podem ser observados os pontos $A^{*}$ e $B^{*}$ no primeiro quadrante. No ponto $A^{*}$, as coordenadas indicam que a mudança estrutural e/ou redução do hiato tecnológico ocorrem com uma razão $\left(\frac{\varepsilon}{\pi}\right)$ superior ao processo de convergência de renda $\left(\frac{y_{s}}{y_{n}}\right)$. No ponto $B^{*}$ ocorre o contrário. Nos pontos $C^{*}$ e $D^{*}$ no terceiro quadrante, temos a situação de divergência de renda em relação ao Norte, bem como lagging behind tecnológico. Contudo, no ponto $\mathrm{C}^{*}$ as coordenadas indicam 
uma situação mais crítica da economia em termos de mudança estrutural e hiato tecnológico do que em relação ao ponto $D^{*}{ }^{35}$

\section{Considerações Finais}

Este artigo teve como objetivo apresentar um modelo macrodinâmico Kaldoriano em que o processo de convergência ou divergência entre o Norte (desenvolvido) e o Sul (em desenvolvimento) é uma função da mudança estrutural e do hiato tecnológico. Neste modelo, o setor industrial é fundamental para a convergência de renda e catching up tecnológico do Sul ao longo do tempo. Isso porque o processo de crescimento econômico na tradição Kaldoriana é setor específico e é neste setor que há mais oportunidades para a acumulação de capital, economias de escala estáticas e dinâmicas, progresso tecnológico mais intenso e efeitos transbordamentos.

A redução do hiato tecnológico depende dos spillovers que ocorrem nesse setor e do maior nível de desenvolvimento do SI. Para que esse processo seja bem sucedido, há a necessidade do aumento do estoque de capital humano, o qual influencia de forma importante a capacidade de assimilação de conhecimento dos trabalhadores e organizações.

Nesse contexto, é possível verificar que há uma conexão importante do modelo desenvolvido com a abordagem da complexidade econômica de

${ }^{35}$ Não é objetivo do presente trabalho a análise empírica sobre as relações teóricas desenvolvidas. Entretanto, para uma análise empírica de como o Sistema Nacional de Inovações pode influenciar as elasticidades renda do comércio internacional e o processo de catching up, recomendamos Romero et al. (2011). Neste trabalho pode-se observar que quanto maior o nível tecnológico das exportações, maior sua elasticidade-renda, de forma a relaxar a restrição externa ao crescimento. O que foi verificado pelos autores foi que o maior desenvolvimento do SI impulsiona o crescimento das exportações de média/alta tecnologia, ao mesmo tempo em que proporciona a redução das importações desses bens. Jayme Jr. e Resende (2009) constataram que países da OCDE, onde o SI é mais desenvolvido, existem saldos externos estruturalmente superavitários para a categoria de bens de maior conteúdo tecnológico. O oposto é observado no Brasil, onde o SI é menos desenvolvido, segundo os autores. Dessa forma, o processo de convergência do país para patamares mais elevados de renda per capita não é possível. Para uma análise de como a indústria manufatureira e a taxa de câmbio real influenciam o processo de crescimento econômico em diferentes níveis de hiato tecnológico, ver Gabriel et al. (2017). Para estes últimos autores, quanto maior o hiato tecnológico dos países, maior o efeito (defasado) da taxa de câmbio real depreciada sobre o processo de crescimento. Além disso, para os países em desenvolvimento, a indústria manufatureira foi o principal setor a influenciar o crescimento econômico para o período de estudo analisado. 
Hausmann e Hidalgo et al. (2011), cuja produção de um determinado bem requer capacitações individuais e organizacionais para desenvolver, selecionar e aplicar o conhecimento relevante para cada manufatura (Hausmann e Hidalgo et. al. 2011).

Além de influenciar o processo de inovação nas duas regiões, o capital humano possui dois novos canais potenciais para afetar a estrutura produtiva. O primeiro canal se dá por meio do chamado "efeito Stiglitz", em que o capital humano pode influenciá-la por meio de uma maior diversificação de produtos demandados. O segundo canal ocorre por meio do "efeito Schumpeter-Stiglitz", o qual implica o aumento das inovações nos lançamentos de novos produtos em termos agregados.

A condição de equilíbrio de longo prazo apresentou equilíbrios múltiplos. No primeiro equilíbrio o sistema dinâmico é estável e no segundo equilíbrio este sistema é instável. No primeiro caso, considera-se que o Sul está realizando esforços para o desenvolvimento do seu SI para um dado nível de hiato tecnológico. Neste cenário, a participação da indústria na economia é elevada e o SI é superior ao nível de hiato tecnológico existente.

Levando-se em conta as condições necessárias e suficientes do modelo para uma situação de forging ahead, ou seja, com convergência de renda e catching up tecnológico em condições de ausência de restrição externa ao crescimento, pôde-se verificar que há combinações não mutuamente excludentes relacionadas às possíveis políticas econômicas a serem adotadas pelo Sul no que diz respeito ao ritmo de mudança estrutural, à melhoria do capital humano e ao grau de desenvolvimento do Sistema Nacional de Inovação $(S I)$.

Por fim, vale ressaltar que a análise do conjunto desses efeitos implica haver um campo de pesquisa empírico a ser explorado no que diz respeito à influência do capital humano sobre as possibilidades de diversificação e inovação nas estruturas produtivas em diferentes níveis de desenvolvimento do SI e hiato tecnológico. O sucesso do processo de difusão, imitação e internalização das inovações tecnológicas em termos do aumento da produtividade dependem em larga medida do maior desenvolvimento do SI, o qual apresentou ser uma das condições importantes para o aumento das atividades inovativas do Sul. Apesar de termos apresentando sua importância em termos analíticos dentro de uma estrutura formal específica, há a necessidade de investigações empíricas. 


\section{Referências}

Abramovitz, M. A. 1986. Catching Up, Forging Ahead and Falling Behind, Journal of Economic History 46: 385-406.

Barbosa Filho, N.H. Exchange rates, growth and inflation. 2006. In: Conference on Development and Change, Campos do Jordão. Disponível: em http://www.policyinnovations.org/ideas/policy_library/data/01383/ res/

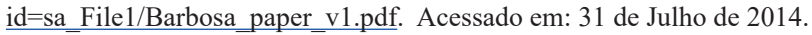

Botta, A. 2012. Is Latin American Structuralism Still Relevant? A Theoretical Dissertation on Structural Change and Economic Development. LAP LAMPERT Academic Publishing GmbH \& Co. KG.

Botta, A. 2009. A structuralist north-south model on structural change, economic growth and catching-up. Structural change and Economic Dynamics 20:61-73.

Caniëls, M. e Verspagen, B. 2001. Barriers to knowledge spillovers and regional convergence in an evolutionary model. Journal of Evolutionary Economics 11: 307-329.

Castellacci, F. 2002. Technology Gap and Cumulative Growth: Models and outcomes. International Review of Applied Economics, 16(3): 333-346.

Cimoli, M. Porcile, G. e Rovira, S. 2010. Structural change and the BOP constraint: why did Latin America fail to converge? Cambridge Journal of Economics 34: 389-411.

Cohen, W.M. \& Levinthal, D. 1990. Absorptive Capacity: A New Perspective on Learning and Innovation. Administrative Science Quarterly 35: 128-152.

Cohen, W.M. \& Levinthal, D. 1989. Innovation and learning: The two faces of R\&D, in The Economic Journal 99: 569-96.

Dahlman, C. J. e Nelson R. 1995. Social Absorption Capability, National Systems and Economic Development in Ho Koo - Perkins ( a cura di), Social capability and long-term economic growth, St. Martin's Press, London.

Dixon, R.J. e A.P. Thirlwall. 1975. A Model of Regional Growth-Rate Differences on Kaldorian Lines. Oxford Economic Papers 11:201-214.

Dosi, G., Freeman, C. e Fabiani, S. 1994. The Process of Economic Development: Introducing Some Stylized Facts and Theories on Technologies, Firms and Institutions. Industrial and Corporate Change 3(1).

Dosi, G., Pavitt, K. e Soete, L. 1990. The economics of technological change and international trade, Brighton: Wheatshaf. Economic Review 34. Economica 61: 237-51.

Edquist, C. e Johnson, B. 1997. Institutions and organizations in System of Innovation. In: Edquist, C. System of Innovation: Technologies, institution and organizations, London and Washington: Pinter.

Ferrari, M. A. R; Freitas, F. N. P; Barbosa-Filho, N. H. 2013. A taxa de câmbio real e a restrição externa: uma proposta de releitura com elasticidades endógenas. Revista de Economia Política 33, 1 (130): 60-81, jan-mar.

Ferrari, M. A. R; Freitas, F. N. P; Barbosa-Filho, N. H. 2010. O papel da taxa de câmbio real nos modelos de restrição externa: uma proposta de releitura. Anais do III Encontro da Associação Keynesiana Brasileira, agosto.

Freeman, C. 1995. The National System of Innovation in Historical Perspective. Cambridge Journal of Economics 19: 5-24.

Freeman, Christopher e Soete, Luc. 2008. A Economia da Inovação Industrial. Campinas: Editora Unicamp.

Gabriel, L.F., Jayme Jr., F. e Oreiro, J.L. 2017. Economic growth, productive structure and real exchange rate: empirical evidences in panel data. Área 4 - Teoria Econômica e Métodos Quantitativos, ANPEC Nordeste (NATAL/RN).

Godin, Benoît e LANE, Joseph P. 2013. "Pushes and Pulls": The Hi(story) of the Demand Pull Modelof Innovation. Project on the Intellectual History of Innovation Working Paper 13.

Gould, D.M. e Ruffin, R.J. 1995. Human Capital, Trade, and Economic Growth, Weltwirtschaftliches Archiv 131: 425-446.

Estud. Econ., São Paulo, vol.49 n.3, p.465-499, jul.-set. 2019 
Hausmann, Ricardo, Hidalgo, César A., Bustos, Sebastián, Coscia, Michele, Chung, Sarah, Jimenez, Juan, Simoes, Alexander, Yildirim, Muhammed A. 2011. The atlas of Economic Complexity - Mapping paths to prosperity. Puritan Press.

Jayme Jr., F. G.; Resende, M. F. C. 2009. Crescimento econômico e restrição externa: teoria e a experiência brasileira, In: Michel, R.; Carvalho, L. (Org) Crescimento econômico: setor externo e inflação, Rio de Janeiro: IPEA. Kaldor, N. 1957. A model of economic growth, Economic Journal, n.67, 591-624.

Kaldor, N. 1966. Causes of the slow rate of economic growth of the United Kingdom, Cambridge: Cambridge University Press.

Krugman, P. 1989. Differences in income elasticities and trends in Real exchange rates. European Economic Review, 33: 1031-1054. North-Holland.

Lall, Sanjaya. 1992. Technological Capabilities and Industrialization. World Development 20(2): 165-186.

León-Ledesma, M. A. 2002. Accumulation, innovation and catching up: an extended cumulative growth model. Cambridge Journal of Economics 26: 201-216.

Marconi, N. 2012. The industrial equilibrium exchange rate in Brazil: an estimation. Brazilian Journal of Political Economy, vol. 32, nº 4 (129), pp. 656-669, October-December.

McCombie, J. e Roberts, M. 2002. The role of the balance of payments in economic growth. In: Setterfield, M. (org.). The Economics of Demand Led-Growth: challenging the supply side vision of the long run. Edward Elgar: Aldershot, 87-114.

McCombie, J. e Thirlwall. 1994. Economic growth and the balance of payments constraint. New York: St. Martin's Press.

Missio, F. 2012. Câmbio e crescimento na abordagem keynesiana-estruturalista. Tese de doutoramento em Economia. Belo Horizonte: Cedeplar/UFMG.

Missio, F. Araújo, R. Jayme Jr., F. 2017. Endogenous elasticities and the impact of the real exchange rate on structural economic dynamics. Structural Change and Economic Dynamics 42: 67-75.

Missio, Fabricio J.; Gabriel, Luciano F. 2016. Real exchange rate, technological catching up and spillovers in a balance-of-payments constraint growth model. Economi $A$ (Brasília) 01: 01-20.

Missio, F., Jayme Jr., F, Conceição, O. 2015. O problema das elasticidades nos modelos de crescimento com restrição externa: contribuições ao debate. Estudos Econômicos, São Paulo, 45(2): 317-346, abr.-jun.

Mowery, D. e Rosenberg, N., 1979. The influence of market demand upon innovation: a critical review of some recentempirical studies. Research Policy 8 (2): 102-153.

Narula, R. 2004. Understanding Absorptive Capacities in an Innovation Systems Context: Consequences for Economic and Employment Growth. DRUID Working Paper 04-02, December.

North, D. 1990. Institution, Institutional Change and Economic Performance, Cambridge: Cambridge University Press.

Oreiro, José Luís, Nakabashi, Luciano, Silva, Guilherme Jonas Costa, e Souza, Gustavo José Guimarães e. 2012. The economics of demand-led growth. Theory and evidence for Brazil. Cepal Review, no. 106 - April.

Oreiro, J.L. 2016. Macroeconomia do Desenvolvimento - Uma Perspectiva Keynesiana. Editora LTC: Rio de Janeiro-RJ.

Romero, J. P., Silveira, F. e Jayme, Jr. 2017. Mudança estrutural, sistema nacional de inovações e restrição do balanço de pagamentos: teoria e implicações de política. Série Working Paper BNDES/ANPEC No. 17, set.

Schumpeter, J. 1997. Teoria do Desenvolvimento Econômico. Editora Nova Cultural Ltda. São Paulo-SP.

Setterfield, M. (Ed.) 2002. The Economics of Demand-Led Growth: challenging the supply-side vision of the long run (Cheltenham, Edward Elgar), 129-152.

Setterfield, M. 1997. Rapid Growth and Relative Decline: Modelling Macroeconomic Dynamics with Hysteresis, London, Macmillan. 
Stiglitz, Joseph. 1993. Endogenous Growth and Cycles. NBER Working Paper 4286, March.

Szirmai, A. 2012. Industrialization as an engine of growth in developing countries, 1950-2005. Structural Change and Economic Dynamics 23: 406- 420.

Thirlwall, A, P. 2005. A natureza do crescimento econômico: um referencial alternativo para compreender o desempenho das nações. Brasília: IPEA. 112p.

Thirlwall, A. P. 1997. Reflections on the Concept of Balance-of-Payments-Constrained Growth. Journal of Post Keynesian Economics Vol. 19(3): 377-385 (Spring 1997).

Thirlwall, A.P. 2011. The balance of payments constraint as an explanation of international growth rates differences, Banca Nazionale del Lavoro Quarterly Review, v, 128, p, 45-53, 1979, In: PSL Quarterly Review 64(259): 429-438.

UNCTAD. 2005. Issues Paper on Bridging the technology gap. UNITED NATIONS CONFERENCE ON TRADE AND DEVELOPMENT November, Morocco, 2005.

Verspagen, B. 1993. Uneven growth between interdependent economies. London: Averbury.

Welfens, Paul J. J. Innovations in Macroeconomics. Third Edition. 2010.

Zahra, Shaker A. e Gerard, George. 2002. Absorptive Capacity: A review, reconceptualization and extension. Academy of Management Review 27(2): 185-203.

\section{APÊNDICE A}

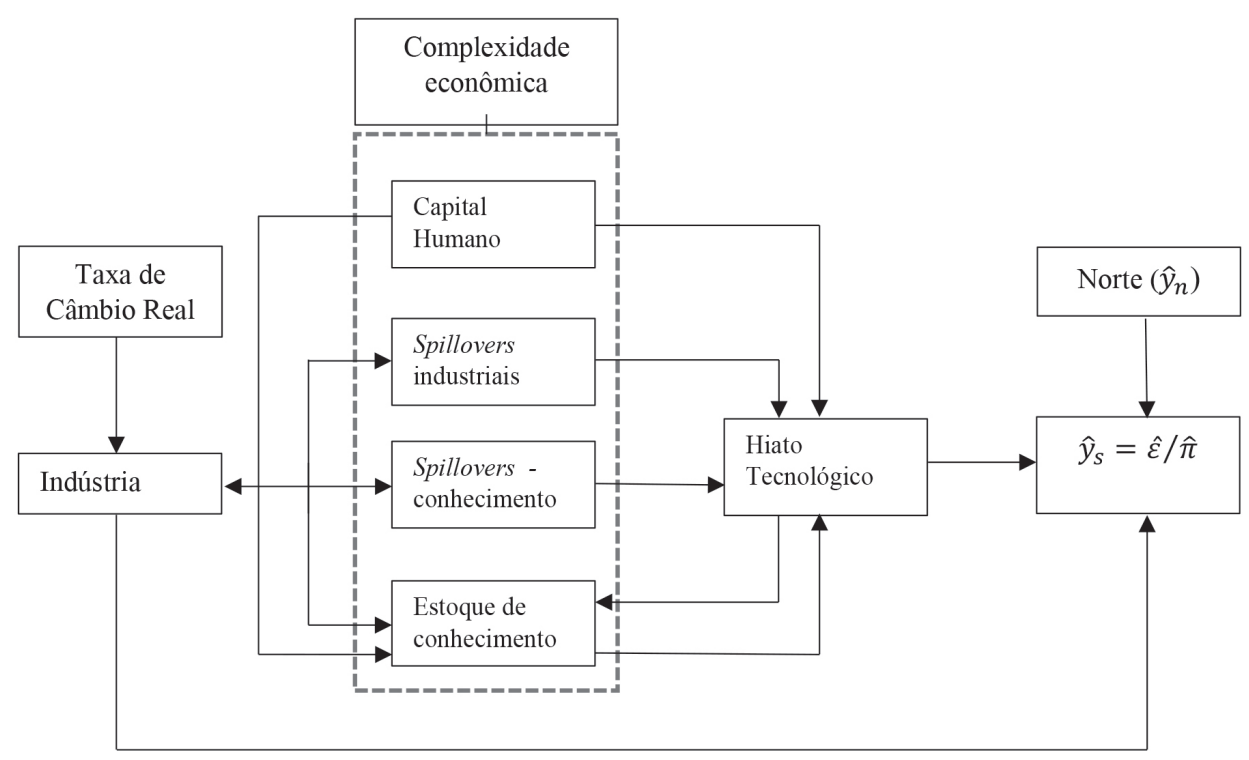

Figura 1 - Taxa de Câmbio Real, Indústria, Spillovers e Restrição Externa

Fonte: Elaboração própria. 